\title{
Immunopathologic Studies in Relapsing Polychondritis
}

\author{
Jerome H. Herman and Marie V. Dennis \\ From the Division of Immunology, Department of Internal Medicine, \\ University of Cincinnati Medical Center, Cincinnati, Ohio 45229
}

A B S T R A C T Serial studies have been performed on three patients with relapsing polychondritis in an attempt to define a potential immunopathologic role for degradation constituents of cartilage in the causation and/or perpetuation of the inflammation observed. Crude proteoglycan preparations derived by disruptive and differential centrifugation techniques from human costal cartilage, intact chondrocytes grown as monolayers, their homogenates and products of synthesis provided antigenic material for investigation. Circulating antibody to such antigens could not be detected by immunodiffusion, hemagglutination, immunofluorescence or complement mediated chondrocyte cytotoxicity as assessed by ${ }^{51} \mathrm{Cr}$ release. Similarly, radiolabeled incorporation studies attempting to detect de novo synthesis of such antibody by circulating peripheral blood lymphocytes as assessed by radioimmunodiffusion, immune absorption to neuraminidase treated and untreated chondrocytes and immune coprecipitation were negative.

Delayed hypersensitivity to cartilage constituents was studied by peripheral lymphocyte transformation employing $\left[{ }^{3} \mathrm{H}\right]$ thymidine incorporation and the release of macrophage aggregation factor. Positive results were obtained which correlated with periods of overt disease activity. Similar results were observed in patients with classical rheumatoid arthritis manifesting destructive articular changes. This study suggests that cartilage antigenic components may facilitate perpetuation of cartilage inflammation by cellular immune mechanisms.

\section{INTRODUCTION}

Relapsing polychondritis is a relatively rare disorder characterized by prominent inflammation of cartilagenous structures. Though cartilage inflammation predominates, one may observe ocular and cardiac involvement as well

This work was presented in part at the American Rheumatism Association meeting, Washington, D. C., January 1971. (1971. Arthritis Rheum. 14 : 166.)

Dr. Herman is a Post-Doctoral Fellow of the Arthritis Foundation.

Received for publication 1 August 1972 and in revised form 24 October 1972. as hematologic and serologic disturbances. There is little insight into etiologic or pathophysiologic factors operative in this disease. A pathologic similarity has been shown to exist between polychondritis and the experimental papain (1) and hypervitaminosis-A (2) induced depletion of cartilaginous matrix as well as the model of complement-dependent cartilage lysis in vitro, mediated by anti-cell membrane antibody $(3,4)$. However, the inflammation with predominant round cell infiltration and degeneration of chondrocytes observed in polychondritis are conspicuous differences.

It is of interest that diseases such as rheumatoid arthritis, Sjögren's syndrome, and lupus erythematosus in which immunologic events appear to play a significant role in the mediation of inflammation may coexist with polychondritis. However, other than an inconclusive report by Dolan, Lemmon, and Teitelbaum (5), there has been no apparent attempt to incriminate such immunopathologic events in the pathogenesis of this disease. In the present report, serial immunologic studies performed on three patients with polychondritis are presented in an attempt to define potential mechanisms operative in the causation and/or perpetuation of the cartilage inflammation observed.

\section{METHODS}

Cartilage antigen preparation. Human cartilage antigens were derived from two sources. The method of Malawista and Schubert (6) employing water extraction with high speed homogenization was utilized to secure crude proteoglycan $(P G)^{1}$ from human costal cartilage. Protein polysaccharide light (PP-L) and heavy (PP-H) derivatives were prepared as described by Gerber, Franklin, and Schubert ( 7$)$ based upon differential centrifugation of PG.

Chondrocytes, asepticaly isolated from human articular cartilage by collagenase digestion (8) were maintained in monolayer culture employing Eagle's minimum essential medium $^{2}$ containing $20 \%$ fetal calf serum, $l$-glutamine, peni-

'Abbreviations used in this paper: ANA, antinuclear antibody ; MCP, metacarpophalangeal joints; PG, proteoglycan; PHA, phytohemagglutinin; PIP, proximal interphalangeal joints; $\mathrm{PP}-\mathrm{H}$, protein polysaccharide heavy derivatives; PP-L, protein polysaccharide light derivatives; SCAT, sheep cell agglutination tests; TCA, trichloroacetic acid.

${ }^{2}$ Grand Island Biological Co., Grand Island, N. Y. 
cillin, streptomycin, and mycostatin. Subculturing was undertaken as necessary. Studies were performed upon intact chondrocytes, their mechanical homogenates and products of chondrocyte synthesis derived from ultrafiltration of growth media at time of biweekly change.

Cartilage antibody preparation. Anti-proteoglycan (antiPG) antisera was obtained by hyperimmunizing rabbits to PG and PP-L, both of which had been pretreated with hyaluronidase $^{3}$ (9) and incorporated into complete Freund's adjuvant. Antisera was concentrated by $40 \%$ ammonium sulfate precipitation and repeatedly absorbed with lyophilized normal human serum and hyaluronidase. By immunoelectrophoresis, these antisera produced two lines on reaction with hyaluronidase treated $\mathrm{PG}$ and $\mathrm{PP}-\mathrm{L}$ as has been reported previously (10). When reacted by immunodiffusion with the chondrocyte culture media concentrate, a single line resulted indicating the ability of these cells to synthesize $\mathrm{PG}$.

Dectection of anti-cartilage antibody. Several techniques were employed in an attempt to detect circulating antibody to cartilage constituents in serial serum specimens from the polychondritis patients. Immunodiffusion and tanned cell hemagglutination studies were performed employing hyaluronidase-treated and untreated cartilage antigen preparations (9). Indirect immunofluorescent techniques were undertaken utilizing both fixed and viable chondrocytes as a source of antigen. Slides were read on a AO Fluorolume fluorescent microscope ${ }^{4}$ using BG-12 and Corning no. 5113 exciter filters and an Eastman Kodak no. 15 barrier filter.

On the assumption that circulating antibody to cartilage components might not be detectable because of specific in vivo binding to antigen, an attempt was made to demonstrate such antibody in vitro by means of its synthesis by peripheral blood lymphocytes, employing $\left[{ }^{14} \mathrm{C}\right]$ amino acid incorporation technics reported previously (11). The ${ }^{14} \mathrm{C}$ protein synthesized de novo was chromatographically purified with DEAE and G-200 chromatography into specific immunoglobulin classes and this radio-labeled material utilized in three types of experiments: (a) Radio-immunodiffusion was performed in which labelled immunoglobulin and "cold" rabbit anti-human PG antibody were diffused against hyaluronidase treated $\mathrm{PG}$ and PP-L. Radiographic patterns were developed following 4 wk exposure to Polaroid Type 57 Land film, ASA 3,000. (b) Having established an equivalence titration curve for rabbit anti-human $P G$ and hyaluronidase treated PP-L, immune coprecipitation (11) was undertaken with labeled immunoglobulin. Results were contrasted with immunoglobulin synthesized by normal peripheral blood lymphocytes. Following dissolution of washed precipitates in $0.5 \mathrm{~N} \mathrm{NaOH}$ and suspension in Bray's phosphor, liquid scintillation counting was performed using a Mark II Liqid Scintillation System. ${ }^{6}$ (c) Specific polychondritis $\left[{ }^{14} \mathrm{C}\right]$ immunoglobulin adsorption experiments were performed, employing suspensions of neuraminidase treated and untreated chondrocyte preparations $(12)$. $\left[{ }^{14} \mathrm{C}\right]$ immunoglobulins derived from normal individuals served as controls. In a typical experiments 5-10,000 trichloroacetic acid (TCA) precipitable counts were exposed to a $1 \mathrm{ml}$ suspension containing $250 \times 10^{3}$ chondrocytes that had been harvested from monolayers by policing. Following 1-h roller incubation at $37^{\circ} \mathrm{C}$, tubes were centrifuged at $150 \mathrm{~g}$ for 10 min. Cell pellets were washed three times with $1 \mathrm{ml}$ vol of

3 Worthington Biochemical Corp., Freehold, N. J.

- American Optical Corp., Bedford, Mass.

5 Eastman Kodak Corp., Rochester, N. Y.

- Nuclear-Chicago Corp., Des Plaines, Ill. phosphate-buffered saline, the original supernates and washes were pooled, and a portion was removed for scintillation counting. Pellets were dissolved in $0.5 \mathrm{NaOH}$ and suspended in Bray's phosphor, and liquid scintillation counting was performed. Percentage of counts binding to chondrocytes was compared with counts originally added to the culture system as well as those recovered in supernatant portions.

Antibody-mediated cytotoxicity experiments were performed in which chondrocytes, labeled with sodium chromate, ${ }^{51} \mathrm{Cr}(5.0 \mu \mathrm{g} / 1 \mathrm{ml}),{ }^{7}$ were incubated with decomplemented polychondritis or control sera in the presence of fresh rabbit complement. Appropriate volumes of the ${ }^{51} \mathrm{Cr}$ solution were added to the cell suspension to give a final radioactive level of $25 \mu \mathrm{Ci} / 3 \mathrm{ml}$ at a cell concentration of $10^{\mathrm{B}}$ cells $/ \mathrm{ml}$. Cytotoxicity was assessed by determining isotope release after a $1 \mathrm{~h}$ incubation at $37^{\circ} \mathrm{C}$. A Packard gamma scintillation system was employed (Packard Instrument Co., Inc., Downers Grove, Ill.).

Chondrocyte DNA synthesis. To further determine the role of humoral factors, the DNA synthesizing capacity of chondrocytes in suspension culture was determined by pulse labeling for $16 \mathrm{~h}$ with $\left[{ }^{3} \mathrm{H}\right]$ thymidine $^{8}$ (sp. act. $11 \mathrm{Ci} / \mathrm{mmol}$ ) in the presence of decomplemented polychondritis or normal sera substituted for fetal calf serum in the growth media $48 \mathrm{~h}$ previously. Upon termination of the experiments, the cell button was pelleted by centrifuging at $150 \mathrm{~g}$, DNA extracted, and liquid scintillation counting performed utilizing a toluene phosphor (13). In similar experiments, chondrocyte viability was assessed, after sera incubations, by trypan blue staining.

Cartilage antigen induced lymphocyte blastogenesis. The response of the patient's peripheral blood lymphocytes to cartilage antigens and PHA was serially assessed by $\left[{ }^{3} \mathrm{H}\right]$ thymidine incorporation (13) and contrasted with results obtained in 12 normal subjects and 12 patients with rheumatoid arthritis having radiographic evidence of destructive joint lesions. Media was supplemented by either $20 \%$ human $\mathrm{AB}^{+}$or autologous serum, glutamine, and streptomycin. Antigens in addition to phytohemagglutinin $(0.05 \mathrm{ml}, \mathrm{PHA}-\mathrm{M})^{\circ}$ consisted of $\mathrm{PG}(500 \mu \mathrm{g})$ both treated and untreated with hyaluronidase, similarly processed PP-L $(50 \mu \mathrm{g})$, chondrocyte homogenate $(500 \mu \mathrm{g})$, chondrocyte supernate $(500 \mu \mathrm{g})$ and in limited experiments, viable mitomycin $C$ treated chondrocytes (14) which in several instances were also reacted with neuraminidase (12). The quantity of cartilage antigen employed was arrived at empirically based upon maximal response of polychondritis and rheumatoid patients and absence of stimulation in normal control cultures. Dosage range in preliminary testing consisted of the following: PG, 5-500 $\mu \mathrm{g}$; PP-L, 5-100 $\mu \mathrm{g}$; chondrocyte homogenate, $50-1,000 \mu \mathrm{g}$; chondrocyte supernate, 250-2,000 $\mu \mathrm{g}$. Response was dose dependent, i.e., larger or smaller quantities than optimal in general associated with a negative response whereas the optimal dosage gave a positive stimulation. This was particularly noted with the chondrocyte homogenate and supernatant antigens whereas a greater consistency of positivity was observed using PG and PP-L in various dose ranges.

Tests were performed in duplicate or triplicate. At the end of an incubation period of 3 days for PHA and 6 days for cartilage antigens, a $2 \mathrm{~h}$ pulse labeling with $\left[{ }^{3} \mathrm{H}\right]$ thymidine was undertaken after which DNA was extracted and liquid scintillation counting was performed. Significant stimulation

\footnotetext{
${ }^{7}$ Mallinckrodt Chemical Works, St. Louis, Mo.

${ }^{8}$ Schwartz-Mann BioResearch, Orangeburg, N. Y.

${ }^{\circ}$ Difco Laboratories, Detroit, Mich.
} 
was considered to be present if the antigen stimulated culture had twice the incorporation of the control. A second in vitro correlate of delayed hypersensitivity, sensitized lymphocyte release of macrophage aggregation factor (15) was evaluated serially in a single patient and its results correlated with the mitogenic experiments. Comparable quantities of cartilage antigenic constituents were employed.

Patients. Case 1. I. M., a 55-yr-old white male, chain food store manager, noted onset of episodic arthralgias with occasional swelling of the knees and ankles in 1967. In January 1969, the frequency of joint attacks increased with elbows, wrists, metacarpophalangeal (MCP) and proximal interphalangeal (PIP) joints involved. 3 months subsequently, in conjunction with a low grade temperature and malaise, episcleritis occurred followed shortly thereafter by pain and swelling of both ears with compromise of the canals due to collapse (Fig. 1). Audiograms demonstrated a mild high-toned hearing deficit bilaterally. Complete blood count, serum protein determinations, LE preparations, antinuclear antibody (ANA), rheumatoid factor as determined by latex fixation and sensitized sheep cell agglutination (SCAT) tests, serum complement, VDRL, uric acid, liver function studies, and urinalysis were unremarkable. X-rays of the joints were negative. Westergren sedimentation rates, haptoglobulin and orosomucoid levels were elevated and electrocardiogram demonstrated first degree heart block. A short trial of phenylbutazone failed to afford relief and the patient was maintained on salicylates.

Daily low dose steroid was instituted in August 1969 but in ensuing months joint involvement became more widespread with arthralgias of several days duration predominating. In addition the hearing deficit continued to worsen and vertigo and a stenosing tenosynovitis in the region of the distal left forearm developed. A peripheral leukocytosis was noted in face of elevated levels of serum IgG and the C3 component of complement. Steroids were discontinued in early 1970 in face of clinical improvement though musculoskeletal and auricular distress continued to a lesser degree. In May 1970, an ischemic optic neuritis developed which was treated with high dosage corticosteroids but nevertheless blindness ensued in the right eye. In July 1970, the patient experienced a left middle cerebral thrombosis with residual right hemiparesis and an expressive aphasia. Subsequent treatment has consisted of steroids and azathioprine with resultant stability in his clinical status.

Case 2. A. K., a 57-yr-old white male fireman, presented with a history of a transient 3 month episode of polyneuritis and vertigo in 1964. In 1966, mild arthralgia with occasional joint swelling appeared in face of elevated serum IgG, IgA, IgM, and normal complement levels. A diagnosis of possible rheumatoid arthritis was made and short term, low dose steroid therapy instituted. In 1967, fleeting generalized arthralgias with large joint swelling appeared with high temperature. The patient was anemic (hematocrit 30 ) with negative Coombs' test. Bone marrow examination revealed 8-10\% plasma cells. The polyclonal gammopathy persisted. Symptoms largely subsided on low dose steroids but low grade temperature and occasional joint swelling continued. Cardiopulmonary and renal status were unremarkable.

In February 1968, the patient presented with an intractable foot ulcer with complicating osteomyelitis of the fifth digit of the right foot. He was hypertensive and had a diabetic glucose tolerance curve. Latex fixation was positive with a SCAT titer of $1: 28$, serum IgA markedly elevated but ANA, LE prep, VDRL, and cryoglobulin determinations were negative. In ensuing months, transient pulmonary infiltrates were

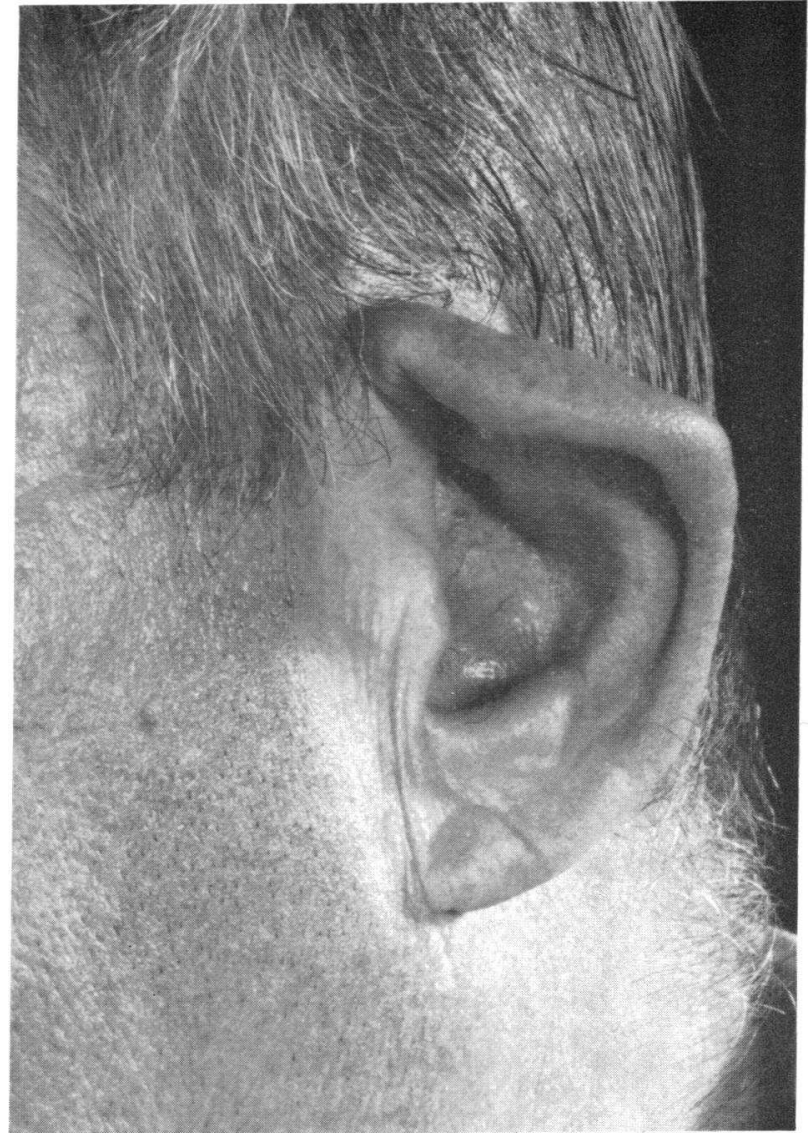

FIGURE 1 Distortion and collapse of the external ear in patient I. M.

noted and poorly defined dermal lesions appeared, biopsy of the latter consistent with acute vasculitis. In 1969, in the presence of pronounced peripheral vascular insufficiency, a right below-knee amputation was performed, the pathologic specimen revealing a necrotizing vasculitis. Shortly thereafter, the patient developed bilateral external auricular pain and inflammation, collapse of nasal cartilage, conjunctivitis, and increased myalgia and arthralgia. Pinna biopsy demonstrated a necrotizing chondritis (Fig. 2). Treatment consisted of high dose steroid with resultant improvement. In early 1970, a left below-knee amputation was performed in face of gangrenous lesions. In July 1970, the patient experienced occlusion of the superior mesenteric artery with infarction of the entire small bowel and succumbed. Necropsy revealed healed polyarteritis of the kidneys and testes, myocarditis, and polychondritis. There was no evidence of rheumatoid arthritis.

Case 3. H. M., a 35-yr-old white female physician, presented with a history of onset in 1966 of polyarticular arthralgias, intermittent swelling of PIP joints, and what appeared to be a tendinitis or tenosynovitis involving the dorsal and ventral surfaces of the wrists. Salicylates afforded relief. Symptoms persisted to a variable degree until April 1971, when two months pregnant, she noted the acute onset of painful swelling involving the right ear in association with an erythematous maculopapular eruption on the upper extremities, malaise, fever, and conjunctivitis. Symp- 


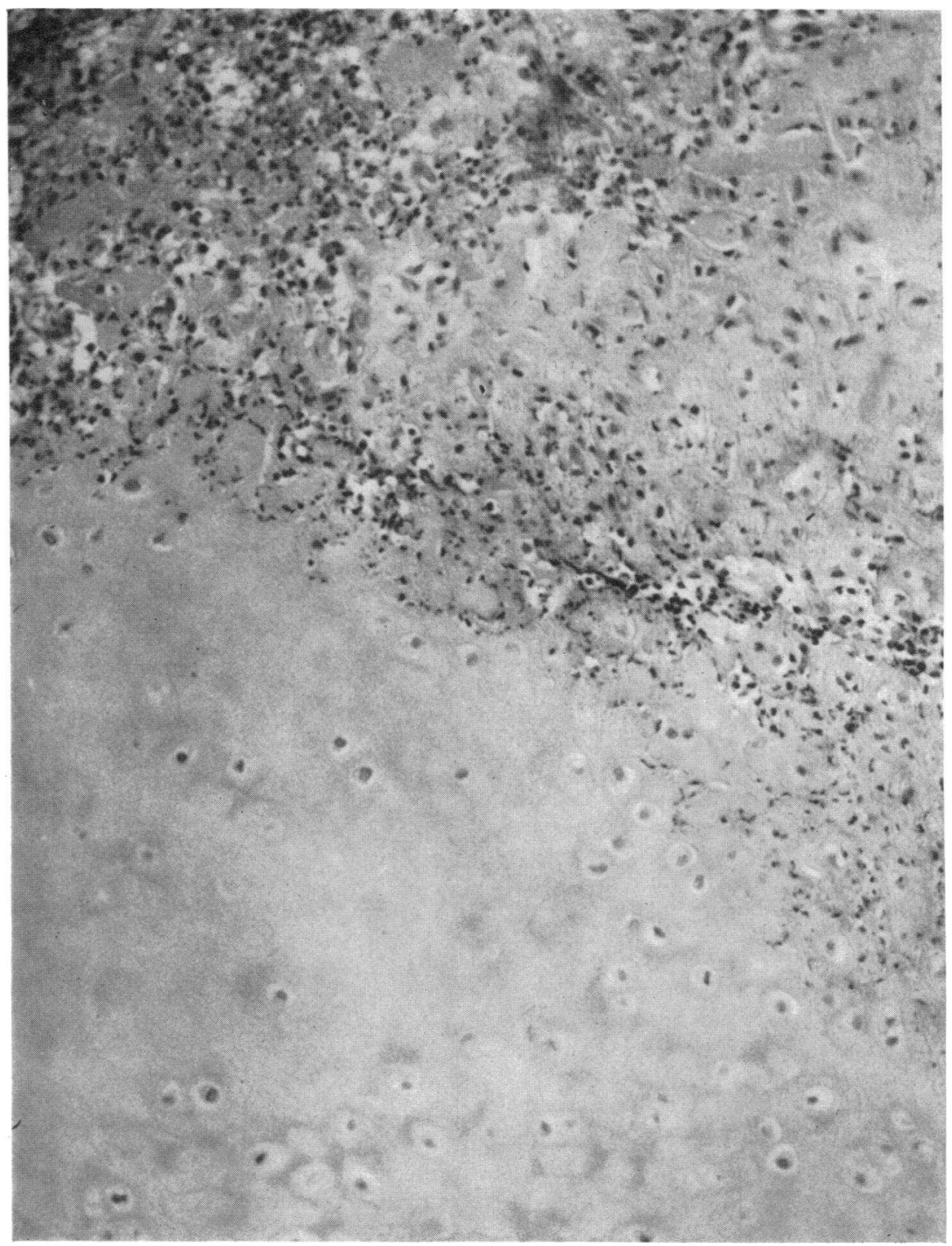

FIGURE 2 Biopsy of external ear cartilage of patient A. K. revealing necrotizing chondritis with inflammatory cell infiltrate, chondrocyte degeneration, and fibrosis. (Magnification $\times 400$ )

toms subsided upon institution of salicylates and local steroid cream. She remained well until July 1971 at which time she developed synovitis of the left wrist and first MCP joint, a painful reddish-blue discoloration and swelling of the left ear, bilateral episcleritis, low grade temperature, and malaise. Biopsy of the involved ear was consistent with polychondritis. Laboratory studies revealed a slightly elevated total protein $(8.2 \mathrm{~g} \%)$, normal blood urea nitrogen, lactate dehydrogenase, serum glutamic oxaloacetic acid-transaminase and alkaline phosphatase levels. Serum immunoglobulin and the C3 component of complement were within normal limits. Westergren sedimentation rate was 36 and haptoglobin increased on immunoelectrophoresis. Peripheral leukocyte level was elevated with a slight left shift, hematocrit 37 and serum iron 57 $\mu \mathrm{g} / 100 \mathrm{ml}$. Urine analysis was normal. Serologic studies revealed a weakly positive latex fixation, negative SCAT, ANA, and antithyroid antibody (ATA) studies. Symptoms once again responded to salicylates and in October 1971 she delivered a $7.5 \mathrm{lb}$ viable fetus showing no clinimal stigmata of polychondritis. Her course has remained stable to date.

\section{RESULTS}

Failure of detection of anti-cartilage antibodies. Immunodiffusion and tanned cell hemagglutination techniques failed to detect antibody to PG, PP-L, or PP-H in serial serum specimens obtained from the patients at times of manifesting active disease as well as during periods of clinical quiescence. Similarly, indirect fluorescent techniques employing both fixed and viable preparations of chondrocytes derived from monolayer cultures failed to demonstrate specific surface, cytoplasmic, or nuclear immunoglobulin binding on comparison with normal serum control specimens. Incubation of ${ }^{\circ} \mathrm{Cr}$-labeled 
chondrocytes with decomplemented polychondritis sera and a source of fresh rabbit complement did not facilitate a degree of release of label differing from normal control sera.

Experiments designed to detect specific anti-PG antibody synthesis by peripheral blood lymphocytes derived from serial bleedings of patients I. M. and A. K. were unsuccessful. No radioactivity was detectable in precipitin lines developing upon reacting labeled plus "cold" rabbit anti-cartilage antibody with hyaluronidase-treated PG and PP-L. In immune coprecipitation experiments, no difference in precipitable radioactivity was observed after the interaction of labeled immunoglobulin synthesized by polychondritis and normal peripheral blood lymphocytes with PP-L and anti-cartilage antibody at equivalence.

Immune adsorption experiments employing suspensions of chondrocytes revealed no significant difference between binding of polychondritis-labeled immunoglobulins as compared with controls. Prior treatment of chondrocytes with neuraminidase did not influence the degree of radiolabeled adsorption.
Effect of polychondritis sera on chondrocyte viability and DNA synthesis. Decomplemented polychondritis sera obtained during variable stages of clinical activity were substituted for fetal calf serum in suspension cultures of chondrocytes $48 \mathrm{~h}$ before a $16 \mathrm{~h}$ pulse labeling with $\left[{ }^{3} \mathrm{H}\right]$ thymidine. These studies failed to demonstrate either enhanced or diminished DNA synthesis when such a substitution was made. The cell viability was similar in cultures augmented with polychondritis sera and fetal calf serum.

Cartilage antigen-induced blastogenesis. The response of the peripheral blood lymphocytes derived from the polychondritis patients to cartilage antigens and PHA was assessed by $\left[{ }^{3} \mathrm{H}\right]$ thymidine incorporation (Table $\mathrm{I}$ ). Results were contrasted with those obtained from 12 normal individuals and 12 patients manifesting definite or classical rheumatoid arthritis by ARA criteria (16). All rheumatoid patients had radiographic evidence of destructive joint changes. Studies were performed at serial monthly intervals on patient I. M. In January 1970, when the patient experienced only periodic mild arthralgias and myalgias, a positive response to $P G$ was

TABLE I

Mitogenic Effect of Cartilage Antigens on Polychondritis Peripheral Lymphocytes

\begin{tabular}{|c|c|c|c|c|c|c|c|c|c|}
\hline \multirow[b]{2}{*}{ Patient } & \multirow[b]{2}{*}{ Date } & \multirow[b]{2}{*}{$\begin{array}{l}\text { Steroid } \\
\text { dosage }\end{array}$} & \multirow[b]{2}{*}{$\begin{array}{c}\text { Serum } \\
\text { supplement }\end{array}$} & \multicolumn{6}{|c|}{ Mean cpm* in control, mitogenic, and antigen-stimulated cultures } \\
\hline & & & & $\begin{array}{l}\text { Control } \\
\text { (without } \\
\text { antigen) }\end{array}$ & PH.A-M & $\begin{array}{c}P G \\
(500 \mu \mathrm{g})\end{array}$ & $\begin{array}{l}\text { PP-I } \\
(50 \mu \mathrm{g})\end{array}$ & $\begin{array}{c}\text { Chondrocyte } \\
\text { homogenate } \\
(500 \mu \mathrm{g})\end{array}$ & $\begin{array}{l}\text { Chondrocyte } \\
\text { supernate } \\
\text { (1 mg) }\end{array}$ \\
\hline & & $m g$ & & & & & & & \\
\hline \multirow[t]{6}{*}{ I. M. } & $1-70$ & 5.0 & $\mathrm{AB}+$ & 3,809 & $\begin{array}{c}434,226 \\
(114)\end{array}$ & $\begin{array}{r}11,226 \\
(3.0)\end{array}$ & & & \\
\hline & $2-70$ & 0 & Autologous & 2,398 & $\begin{array}{c}270,874 \\
(113)\end{array}$ & & $\begin{array}{r}3,597 \\
(1.5)\end{array}$ & & \\
\hline & $3-70$ & 0 & Autologous & 2,605 & $\begin{array}{c}166,720 \\
(64)\end{array}$ & $\begin{array}{r}3,126 \\
(1.2)\end{array}$ & $\begin{array}{r}3,691 \\
(1.4)\end{array}$ & & \\
\hline & $4-70$ & 0 & $\mathrm{AB}+$ & 2,331 & $\begin{array}{c}202,797 \\
(87)\end{array}$ & $\begin{array}{r}3,030 \\
(1.3)\end{array}$ & $\begin{array}{r}2,564 \\
(1.1)\end{array}$ & $\begin{array}{r}4,664 \\
(2.0)\end{array}$ & $\begin{array}{l}6,750 \\
(2.9)\end{array}$ \\
\hline & $5-70$ & 5 & $\mathrm{AB}+$ & 1,323 & $\begin{array}{c}101,548 \\
(76)\end{array}$ & $\begin{array}{r}5,032 \\
(3.8)\end{array}$ & & $\begin{array}{r}11,780 \\
(8.9)\end{array}$ & $\begin{array}{l}4,106 \\
(3.1)\end{array}$ \\
\hline & $6-70$ & 12.5 & $\mathrm{AB}+$ & 1,264 & $\begin{array}{c}102,380 \\
(81)\end{array}$ & $\begin{array}{r}18,928 \\
(15.0)\end{array}$ & $\begin{array}{r}19,003 \\
(15.0)\end{array}$ & $\begin{array}{r}3,420 \\
(2.7)\end{array}$ & $\begin{array}{l}8,980 \\
(7.1)\end{array}$ \\
\hline \multirow[t]{2}{*}{ A. $\mathrm{K}$. } & $2-70$ & 30.0 & Autologous & 3,322 & $\begin{array}{c}129,558 \\
(39)\end{array}$ & & $\begin{array}{r}5,667 \\
(1.7)\end{array}$ & & \\
\hline & $4-70$ & 22.5 & $\mathrm{AB}+$ & 1,204 & $\begin{array}{c}68,628 \\
(57)\end{array}$ & $\begin{array}{r}1,346 \\
(1.1)\end{array}$ & $\begin{array}{r}1,327 \\
(1.1)\end{array}$ & $\begin{array}{r}16,861 \\
(14.0)\end{array}$ & $\begin{array}{l}2,048 \\
(1.7)\end{array}$ \\
\hline \multirow[t]{3}{*}{ H. M. } & $7-71$ & 0 & $\mathrm{AB}+$ & 3,340 & $\begin{array}{r}161,656 \\
(48.4)\end{array}$ & $\begin{array}{r}3,474 \\
(1.0)\end{array}$ & $\begin{array}{r}3,774 \\
(1.1)\end{array}$ & & $\begin{array}{c}29,025 \\
(8.7)\end{array}$ \\
\hline & $10-71$ & 0 & $\mathrm{AB}+$ & 2,280 & $\begin{array}{r}121,752 \\
(53.4)\end{array}$ & $\begin{array}{r}4,788 \\
(2.1)\end{array}$ & $\begin{array}{r}3,420 \\
(1.5)\end{array}$ & & $\begin{array}{r}3,192 \\
(1.4)\end{array}$ \\
\hline & $2-72$ & 0 & $\mathrm{AB}+$ & 1,464 & $\begin{array}{c}99,552 \\
(68)\end{array}$ & $\begin{array}{r}1,903 \\
(1.3)\end{array}$ & $\begin{array}{r}2,152 \\
(1.5)\end{array}$ & & $\begin{array}{r}2,342 \\
(1.6)\end{array}$ \\
\hline
\end{tabular}

* Data based on duplicate or triplicate analysis. Figures in parentheses beneath mean cpm represent dégree of stimulation times basal control levels. 
elicited, AB positive serum being employed as supplement. In the ensuing 2 months, negative results were obtained upon stimulation with PG and PP-L, an autologous serum being employed as supplement. As an inhibitor substance impairing lymphocyte transformation upon exposure to specific antigen has been described in other autologous culture systems (17-22), in subsequent cultures only $\mathrm{AB}$ positive sera was employed. In April, though failing to respond to PG and PP-L, the chondrocyte homogenate and culture supernatant results were positive. In the months of May and June, during a clinical exacerbation characterized by optic neuritis, synovitis, and fever, positive responses were obtained to all antigens tested. During this period, stimulation with viable mitomycin-treated chondrocytes and mitomycinneuraminidase-treated cells was negative. Stimulation of lymphocytes with hyaluronidase alone failed to induce blast transformation. Two lymphocyte transformation studies were performed on patient A. K. The initial experiment was performed during a period of clinical stability, the patient receiving $30 \mathrm{mg}$ of prednisone daily. At this time his peripheral blood lymphocytes failed to respond to variable quantities of hyaluronidase treated PP-L or hyaluronidase alone. 2 months before his death however, the patient, though demonstrating a negative response to PG, PP-L, and culture supernatant, had a positive stimulation to chondrocyte homogenate with a value 14 times base level. Three studies were performed on patient H. M. When manifesting clinical activity, a positive response to chondrocyte culture supernate was obtained with a value 8.7 times base level. 4 months later, with symptoms controlled with salicylates, only a weekly positive response to $P G$ antigen was obtained followed by negative results during a subsequent inactive phase. PHA response was normal in each of the three patients.

Macrophage aggregation factor was studied in patient H. M. in conjunction with the mitogenic experiments. A single positive aggregation response to chondrocyte supernatant antigen was noted at time of the initial bleeding, correlating with the positive blastogenic result.

Control stimulation studies performed on 12 normal adults using a similar battery of cartilage antigens were consistently negative except for a single low grade positive response using the chondrocyte supernatant antigen (Table II). A repeat study in this individual gave a negative result. Transformation to one or more cartilage antigens was noted however, in 9 of 12 of the rheumatoid patients. Response of 5 of 12 patients to $\mathrm{PG}$ was positive with a mean incorporation of 4.0 times control; 3 of 12 responded to PP-L, mean response of $6.6 ; 7$ of 12 to chondrocyte culture supernate, mean value of 9.6 ; 4 of 12 to chondrocyte homogenate, mean response 6.3 times base. A detailed evaluation of the immunologic significance of degradation products of cartilage as regards causation and perpetuation of rheumatoid joint inflammation will be published independently (23).

\section{DISCUSSION}

The pathophysiologic basis underlying the development of the destructive cartilagenous changes observed in relapsing polychondritis is unknown. An explanation must be afforded for not only loss of metachromatic staining of matrix but its fragmentation in conjunction with chondrocyte dissolution, mononuclear cell infiltration and consequent fibrosis.

Involvement of a proteolytic process is inferred by experimental studies. The capacity of lysosomal enzymes to degrade the proteoglycans of cartilage matrix has been shown in in vitro studies by Ziff, Gribetz, and Lospalluto (24) and Weissman and Spillberg (25). The intravenous injection of crude papain (2) and the experimental production of a state of hypervitaminosis A (3) have also induced a transient dissolution of cartilagenous matrix secondary to loss of glycosaminoglycans. Associated irreparable chondrolysis has been produced by Lack (26) through plasmin activation by trauma or streptococcal or staphlococcal kinases in synovial fluid. Harris, DiBona, and Krane (27) have shown that similar changes could be induced by a collagenase synthesized by rheumatoid synoviocytes in in vitro culture experiments.

Although such evidence suggests involvement of a proteolytic process in the pathogenesis of polychondritis, there is limited insight into how such enzyme activation, primarily or secondarily induced, occurs. A secondary chemical mediation is suggested by experimental studies of Moskowitz et al. (28) in which components of cartilage have been shown capable of activating Hageman factor and the generation of kinins. In the present study, in limited experiments we have not been able to identify a humoral factor analogous to the papain model. Sera derived at times of varying stages of clinical activity failed to affect either chondrocyte DNA synthesis or viability.

Though cartilage has been regarded as an immunologically "privileged" tissue due to its lack of vascularity $(29,30)$, it is tempting to incriminate immunologic events in the pathogenesis of polychondritis. If the components of cartilage matrix are enzymatically degraded thereby allowing exposure of chondrocytes, transplantation immunity is capable of being engendered with eventual chondrolysis (31). Furthermore, the proteoglycan component of cartilage matrix has been shown to be antigenic $(9,10,32)$, the antigenicity appearing to reside at the site of union of the glycosaminoglycan and protein moieties. Chondroitin sulfate alone is not antigenic. In a study by Glynn and Holborow (33), how- 
TABLE II

Mitogenic Effect of Cartilage Antigens on Normal Peripheral Lymphocytes

\begin{tabular}{|c|c|c|c|c|c|c|c|}
\hline \multirow[b]{2}{*}{ Test } & \multirow[b]{2}{*}{$\begin{array}{c}\text { Serum } \\
\text { supplement }\end{array}$} & \multicolumn{6}{|c|}{ Mean cpm* in control, mitogenic, and antigen-stimulated cultures } \\
\hline & & $\begin{array}{l}\text { Control } \\
\text { (without } \\
\text { antigen) }\end{array}$ & PHA-M & $\begin{array}{c}\text { PG } \\
(500 \mu \mathrm{g})\end{array}$ & $\begin{array}{l}\text { PP-L } \\
(50 \mu \mathrm{g})\end{array}$ & $\begin{array}{l}\text { Chondrocyte } \\
\text { homogenate } \\
(500 \mu \mathrm{g})\end{array}$ & $\begin{array}{l}\text { Chondrocyte } \\
\text { supernate } \\
(1 \mathrm{mg})\end{array}$ \\
\hline M. D. & $\mathrm{AB}+$ & 1,489 & $\begin{array}{c}93,807 \\
(63)\end{array}$ & $\begin{array}{l}2,025 \\
(1.4)\end{array}$ & $\begin{array}{l}1,444 \\
(1.0)\end{array}$ & $\begin{array}{l}1,385 \\
(0.93)\end{array}$ & $\begin{array}{l}2,984 \\
(2.0)\end{array}$ \\
\hline M. D. (repeat) & $\mathrm{AB}+$ & 3,624 & $\begin{array}{c}172,502 \\
(48)\end{array}$ & $\begin{array}{l}3,733 \\
(1.0)\end{array}$ & $\begin{array}{l}3,436 \\
(0.95)\end{array}$ & $\begin{array}{l}4,059 \\
(1.0)\end{array}$ & $\begin{array}{l}4,342 \\
(1.2)\end{array}$ \\
\hline J. H. & $\mathrm{AB}+$ & 1,193 & $\begin{array}{c}25,291 \\
(21)\end{array}$ & $\begin{array}{l}1,216 \\
(1.0)\end{array}$ & $\begin{array}{l}1,766 \\
(1.5)\end{array}$ & $\begin{array}{l}1,200 \\
(1.0)\end{array}$ & $\begin{array}{r}1,002 \\
(0.84)\end{array}$ \\
\hline M. P. & $\mathrm{AB}+$ & 2,430 & $\begin{array}{c}157,221 \\
(65)\end{array}$ & $\begin{array}{l}3,013 \\
(1.2)\end{array}$ & $\begin{array}{l}3,062 \\
(1.3)\end{array}$ & $\begin{array}{l}1,510 \\
(0.62)\end{array}$ & $\begin{array}{l}2,600 \\
(1.1)\end{array}$ \\
\hline D. W. & $\mathrm{AB}+$ & 2,596 & $\begin{array}{c}275,954 \\
(106)\end{array}$ & $\begin{array}{l}2,518 \\
(0.97)\end{array}$ & $\begin{array}{l}2,682 \\
(1.0)\end{array}$ & $\begin{array}{l}3,297 \\
(1.3)\end{array}$ & $\begin{array}{l}2,492 \\
(0.96)\end{array}$ \\
\hline M. W. & $\mathrm{AB}+$ & 2,033 & $\begin{array}{c}245,586 \\
(121)\end{array}$ & $\begin{array}{l}2,094 \\
(1.0)\end{array}$ & $\begin{array}{l}2,196 \\
(1.1)\end{array}$ & $\begin{array}{l}2,236 \\
(1.1)\end{array}$ & $\begin{array}{l}2,432 \\
(1.2)\end{array}$ \\
\hline B. G. & $\mathrm{AB}+$ & 2,334 & $\begin{array}{c}50,648 \\
(22)\end{array}$ & $\begin{array}{l}1,954 \\
(0.84)\end{array}$ & $\begin{array}{l}4,271 \\
(1.8)\end{array}$ & & $\begin{array}{l}2,562 \\
(1.1)\end{array}$ \\
\hline G. S. & $\mathrm{AB}+$ & 6,389 & $\begin{array}{c}228,726 \\
(36)\end{array}$ & $\begin{array}{l}8,178 \\
(1.3)\end{array}$ & $\begin{array}{l}5,967 \\
(0.93)\end{array}$ & & $\begin{array}{c}11,244 \\
(1.8)\end{array}$ \\
\hline M. K. & $\mathrm{AB}+$ & 4,205 & $\begin{array}{c}110,591 \\
(26)\end{array}$ & $\begin{array}{l}5,803 \\
(1.4)\end{array}$ & $\begin{array}{l}5,382 \\
(1.3)\end{array}$ & & $\begin{array}{l}5,298 \\
(1.3)\end{array}$ \\
\hline A. H. & $\mathrm{AB}+$ & 7,929 & $\begin{array}{c}363,148 \\
(46)\end{array}$ & $\begin{array}{l}6,954 \\
(0.88)\end{array}$ & $\begin{array}{l}8,718 \\
(1.1)\end{array}$ & & $\begin{array}{r}6,185 \\
(0.78)\end{array}$ \\
\hline J. B. & $\mathrm{AB}+$ & 1,984 & $\begin{array}{c}142,252 \\
(72)\end{array}$ & $\begin{array}{l}2,758 \\
(1.4)\end{array}$ & $\begin{array}{l}2,718 \\
(1.4)\end{array}$ & & $\begin{array}{l}2,372 \\
(1.2)\end{array}$ \\
\hline M. Y. & $\mathrm{AB}+$ & 5,613 & $\begin{array}{c}483,840 \\
(86)\end{array}$ & $\begin{array}{l}6,567 \\
(1.2)\end{array}$ & $\begin{array}{l}6,346 \\
(1.1)\end{array}$ & & $\begin{array}{l}6,172 \\
(1.1)\end{array}$ \\
\hline J. F. & $\mathrm{AB}+$ & 3,326 & $\begin{array}{c}155,324 \\
(47)\end{array}$ & $\begin{array}{l}3,480 \\
(1.0)\end{array}$ & $\begin{array}{l}3,958 \\
(1.2)\end{array}$ & & $\begin{array}{l}3,647 \\
(1.1)\end{array}$ \\
\hline
\end{tabular}

* Data based on duplicate or triplicate analysis. Figures in parentheses beneath mean cpm represent degree of stimulation times basal control levels.

ever, a vaccine prepared from group A $\beta$-hemolytic streptococci in the presence of chondroitin sulfate produced precipitating antibody to this polysaccharide. Rabbits immunized systemically with this preparation developed synovial lesions. Immunization with streptococci or chondroitin sulfate alone failed to produce such change. No comment was made as to cartilage pathology. Strobel and Seifert (34) were not able to reproduce these results.

Studies by Lloyd-Roberts (35) and Hultèn and Gellerstedt (36) have shown that intra-articular injections of finely divided homologous or autologous hyaline cartilage could induce a synovitis, its intensity dependent upon the frequency and duration of injection. No cartilagenous lesions were observed. Using homogenized suspensions of autologous canine costal cartilage, Chrisman, Fessel, and Southwick (37) observed that protracted intra-articular injection induced not only synovi- tis but marginal exostosis and cysts. There was, however, no apparent damage to articular weight bearing surfaces as evidenced by gross or microscopic change. Considering the recognized immunogenicity of cartilage constituents and the ability to induce systemic as well as local immunization following intra-articular antigenic challenge (38), it is difficult to understand why an expected immune response failed to induce cartilage degradation. Possibly matrix integrity afforded a protective barrier. Such studies therefore suggest the inability of a potential primary immunologic insult to induce cartilage damage. If immunologic events are operative, they more likely would function in a secondary capacity, that is, function as a means of perpetuating cartilage damage subsequent to alteration in the integrity of this tissue induced by other means.

Several lines of evidence suggest possible immunologic mechanisms operative in relapsing polychondritis. This 
disease not infrequently co-exists with connective tissue disorders such as rheumatoid arthritis, systemic lupus erythematosus and Sjogren's syndrome in which immunologic events are of acknowledged significance in pathogenesis (5). Patient A. K. in our series, appears to be the first documented association with polyarteritis nodosa. The speculations of Christian (39) are intriguing relative to defining an immunologically directed insult against proteoglycans which function as a shared connective tissue constituent common to cartilage, eye, and aorta, all of which may be involved in this disease process. The integrity of cartilage is dependent upon the preservation of its matrix making this structure more vulnerable than the others to damage. It is of interest that cross-reactivity has been shown to exist between streptococcal hyaluronate and a crude proteoglycan preparation of human cartilage (40). The frequency of an antedated or enhanced incidence of streptococcal infections in the polychondritis population has not been evaluated.

Dolan, Lemmon, and Teitelbaum (5) attempted to incriminate immunopathologic events in the pathogenesis of polychondritis. Using sera derived from two patients, they employed immunofluorescence to demonstrate localization of immunoglobulin at the periphery of lacunar spaces and in nuclear and cytoplasmic regions of chondrocytes. The results were inconclusive because of considerable background fluorescence observed in control preparations. Recognizing this difficulty, we resorted to use of isolated chondrocytes for fluorescent experiments.

In the present study, we have been unable to identify either circulating or $\mathrm{PBL}$ synthesized antibody to cartilage matrix or chondrocyte antigenic components. It appears unlikely that physiochemical changes occurring in our lines of cultured chondrocytes are responsible for the negative fluorescent and complement mediated cytotoxicity results as continued synthesis of matrix constituents could be identified.

The cartilage antigens used proved mitogenic to the peripheral blood lymphocytes of our polychondritis patients. It is to be noted that the proteoglycan preparation employed was isolated by disruptive technique and contained contaminants in addition to recognized protein components of cartilage matrix. Prior to absorption of anti-PG antisera with normal human serum, alpha, beta and at times even gamma globulin components could be identified by immunoelectrophoresis. One cannot exclude the possibility that the protein component of proteoglycan subunit or link protein is the antigen inducing response. Nonetheless, the importance lies in the recognition that a constituent or constituents present in normal cartilage were able to induce such a response.

Though blast transformation is not an absolute in vitro correlate of delayed hypersensitivity, it is certainly another parameter of cellular immunity. In a study of the immunologic significance of degradation products of cartilage as regards the causation and/or perpetuation of rheumatoid joint inflammation (23), we performed similar lymphocyte stimulation studies with cartilage antigens and found that the results correlated almost completely with other more conclusive parameters of cellular immunity, that of liberation of macrophage aggregation and cytotoxicity factors. Release of aggregation factor was studied in only one polychondritis patient, being positive at time of initial activity bu negative thereafter during clinical quiescence.

The variability noted as regards the peripheral blood lymphocyte response to cartilage antigen is of interest. Dosage of salicylate or steroid being administered did not appear to be the responsible factor. Autologous serum potentially contained an inhibitor to specific mitogenesis, yet did not alter PHA response. Substrates of unknown composition capable of inhibiting lymphocyte stimulation have been described in the plasma of patients with various disease process (17-22). The periodic positive responses observed with chondrocyte homogenate or products of synthesis in face of negative stimulation to $P G$ and PP-L might reflect either a quantitative antigenic phenomenon or the presence of chondrocyte constituents of antigenic composition other than the mature proteoglycan matrix. No attempt has been made to identify the components of either the chondrocyte homogenate or its synthetic products other than detection of an antigenic constituent reactive by Ouchterlony with absorbed antiPG antisera.

The situation presented in which lack of antigen stimulated response during disease remission and the appearance of such a response during exacerbation is distinctly unusual. There are, however, few reported instances in which serial investigations of delayed hypersensitivity have been reported in human disease. It is conceivable that during period of remission, as a consequence of cessation of further exposure to antigen, that specifically sensitized thymus derived lymphocytes may be at a minimum. An analogous situation may be found in experimental literature in studies of transfer of delayed hypersensitivity to a haptenic constituent in guinea pigs (41). Such a cellular transfer could not be achieved beyond 84 days post initial immunization but could be accomplished a short interval after boosting of the donor animal.

Though unable to identify antibody to cartilage components, lymphocyte sensitization to such antigens appears to be present in relapsing polychondritis as well as in patients with seropositive rheumatoid arthritis having radiographic evidence of destructive joint changes. This would support the hypothesis that immune mechanisms may be involved in the pathogenesis of polychondritis. It would appear unlikely that such a mechanism 
would function in a provocative, causal manner but could be a basis for the perpetuation of cartilage inflammation once its integrity has been altered.

\section{ACKNOWLEDGMENTS}

We acknowledge the cooperation of the Department of Medicine of the Cincinnati Veterans Administration Hospital and Dr. N. R. Abrams for allowing study of their patients. We are grateful to Dr. Evelyn V. Hess for advice and encouragement and for reviewing this manuscript.

This investigation was supported in part by Training Grant AM 05044 from the National Institute of Arthritis and Metabolic Diseases and an Arthritis Foundation Clinical Research Center grant.

\section{REFERENCES}

1. Thomas, L., 1956. Reversible collapse of rabbit ears after intravenous papain and prevention of recovery by cortisone. J. Exp. Med. 104: 245.

2. Thomas, L., R. T. McCluskey, J. L. Potter, and G. Weissmann. 1960. Comparison of the effects of papain and vitamin A on cartilage. I. The effect in rabbits. $J$. Exp. Med. 111: 705.

3. Fell, H. B., R. R. A. Coombs, and J. T. Dingle. 1966. The breakdown of embryonic (chick) cartilage and bone cultivated in the presence of complement sufficient antiserum. I. Morphological changes, their reversibility and inhibition. Int. Arch. Allergy Appl. Immunol. 30: 146.

4. Lachmann, P. J., R. R. A. Coombs, H. B. Fell, and J. T. Dingle. 1969. The breakdown of embryonic (chick) cartilage and bone cultivated in the presence of complement sufficient antiserum. III. Immunological analysis. Int. Arch. Allergy. Appl. Immunol. 36: 469.

5. Dolan, D. L., G. B. Lemmon, Jr., and S. L. Teitelbaum. 1966 Relapsing polychondritis. Analytical literature review and studies on pathogenesis. Am. J. Med. 41: 285.

6. Malawista, I., and M. Schubert. 1958. Chondromucoprotein: new extraction method and alkaline degradation. J. Biol. Chem. 230: 535 .

7. Gerber, B. R., E. C. Franklin, and M. Schubert 1960. Ultracentrifugal fractionation of bovine nasal chondromucoprotein. J. Biol. Chem. 235: 2870.

8. Manning, W. K., and W. M. Bonner, Jr. 1967. Isolation and culture of chondrocytes from human adult articular cartilage. Arthritis Rheum. 10: 235.

9. Sandson, J., L. Rosenberg, and D. White. 1966. The antigenic determinants of the protein-polysaccharides of cartilage. J. Exp. Med. $123: 817$.

10. Loewi, G., and H. Muir. 1965. The antigenicity of chondromucoprotein. Immunology. 9: 119.

11. Herman, J. H., J. Bradley, M. Ziff, and J. D. Smiley. 1971. Response of the rheumatoid synovial membrane to exogenous immunization. J. Clin. Invest. 50: 266.

12. Ray, P. K., H. Gewurz, and R. L. Simmons. 1970. The mechanism of increased sensitivity of neuraminidase treated cells to antibody induced cytolysis. Fed. Proc. 29: 573.

13. Goldman, J. A., A. Litwin, L. E. Adams, R. C. Krueger, and E. V. Hess. 1972. Cellular immunity to nuclear antigens in systemic lupus erythematosus. J. Clin. Invest. $51: 2669$.

14. Bach, F. H., and N. K. Voynow. 1966. One-way stimulation in mixed leukocyte cultures. Science (Wash. D. C.). $153: 545$.
15. Lolekha, S., S. Dray, and S. Gotoff. 1970. Macrophage aggregation in vitro: a correlate of delayed hypersensitivity. J. Immunol. 104 : 296.

16. Ropes, M. W., G. A. Bennet, S. Cobb, R. Jacox, and R. A. Jessar. 1959. The 1958 revision of diagnostic criteria for rheumatoid arthritis. Arthritis Rheum. 2: 16.

17. Paronetto, F., and H. Popper. 1970. Lymphocyte stimulation induced by halothane in patients with hepatitis following exposure to halothane. N. Engl. J. Med. 283: 277.

18. Heilman, D. H., and W. McFarland. 1966. Inhibition of tuberculin-induced mitogenesis in cultures of lymphocytes form tuberculous donors. Int. Arch. Allergy. 30: 58.

19. Levene, G. M., J. L. Turk, D. J. M. Wright, and A. G. S. Grimble. 1969. Reduced lymphocyte transformation due to a plasma factor in patients with active syphilis. Lancet. 2: 246.

20. Silk, M. 1967. Effect of plasma from patients with carcinoma on in vitro lymphocyte transformation. Cancer. 20: 2088 .

21. Knowles, M., D. Hughes, E. A. Caspary, and E. J. Field. 1968. Lymphocyte transformation in multiple sclerosis: inhibition of unstimulated thymidine uptake by a serum factor. Lancet. 2: 1207.

22. Winter, G. C. B., C. F. McCarthy, A. E. Read, and J. M. Yoffey. 1967. Development of macrophages in phytohaemagglutinin cultures of blood from patients with idiopathic steatorrhoea and with cirrhosis. Br. J. Exp. Pathol. 48: 66.

23. Herman, J. H., D. W. Wiltse, and M. V. Dennis. 1972. Immunopathologic significance of cartilage degradation products in rheumatoid joint inflammation. Arthritis Rheum. 15: 375. (Abstr.)

24. Ziff, M., H. J. Gribetz, and J. Lospalluto. 1960. Effect of leukocyte and synovial membrane extracts on cartilage mucoprotein. J. Clin. Invest. 39: 405.

25. Weissmann, G., and I. Spilberg. 1968. Breakdown of cartilage proteinpolysaccharide by lysosomes. Arthritis Rheum. 11: 162.

26. Lack, C. H. 1959. Chondrolysis in arthritis. J. Bone Jt. Surg. B Br. Vol. 41B: 384.

27. Harris, E. D., Jr., D. R. DiBona, and S. M. Krane. 1970. A mechanism for cartilage destruction in rheumatoid arthritis. sirthritis Rheum. 13: 321. (Abstr.)

28. Moskowitz, R. W., H. J. Schwartz, B. Michel, O. D. Ratnoff, and T. Astrup. 1970. Generation of kinin-like agents by chondroitin sulfate, heparin, chitin sulfate and human articular cartilage: possible pathophysiologic implications. J. Lab. Clin. Med. 76: 790.

29. Craigmyle, M. B. L. 1960. A study of cartilage homografts in rabbits sensitized by a skin homograft from the cartilage donor. Transplant. Bull. 26: 150.

30. Gibson, T. 1967. The transplantation of cartilage. $J$. Clin. Pathol. 20 (Suppl.) : 513.

31. Heyner, S. 1969. The significance of the intercellular matrix in the survival of cartilage allografts. Transplantation. 8 : 666 .

32. DiFerrante, N. 1964. Precipitins in the rabbit produced by protein polysaccharide from bovine nasal cartilage. Science (Wash. D. C.). 143: 250.

33. Glynn, L. E., and E. J. Holborow. 1952. Conversion of tissue polysaccharides to auto-antigens by group-A betahaemolytic streptococci. Lancet. 2: 449. 
34. Strobel, V. W., and G. Seifert. 1961. Zur panchondritis rheumatica. $Z$. Rheumaforsch. $20: 247$.

35. Lloyd-Roberts, G. C. 1953. The role of capsular changes in osteoarthritis of the hip joint. J. Bone Jt. Surg. 35B : 627.

36. Hultèn, O., and N. Gellerstedt. 1940. Uber Abnutzungsprodukte in Gelenken und ihre Resorption unter dem Bilde einer Synovitis detritica. Acta. Chir. Scand. 84: 1.

37. Chrisman, O. D., J. M. Fessel, and W. O. Southwick. 1965. Experimental production of synovitis and marginal articular exostoses in the knee joints of dogs. Yalc J. Biol. Med. 37 : 409.
38. Jasin, H. E., and M. Ziff. 1969. Immunoglobin and specific antibody synthesis in a chronic inflammatory focus: antigen induced synovitis. J. Immunol. 102: 355.

39. Christian, C. L. 1970. Discussion of paper: relapsing polychondritis with aortic involvement by Owen, D. S., R. Irby, and E. Toone. Arthritis Rheum. 13: 880.

40. Sandson, J. L., D. Hamerman, R. Jones, R. Janis, and M. Rojkind. 1968. Immunologic and chemical similarities between the streptococcus and human connective tissue. Trans. Assoc. Am. Physicians Phila. 81: 249.

41. Phair, J. P., and F. S. Kantor. 1968. Delayed hypersensitivity. II. Persistence and conjugate specificity of the transfer reaction. J. Immunol. 100: 302 . 